\title{
Renal Circulation in Cirrhosis: Observations Based on Catheterization of the Renal Vein *
}

\author{
William P. Baldus, $\dagger$ William H. J. Summerskill, James C. Hunt, and \\ Frank T. Maher \\ (From the Gastrointestinal Research Unit, the Section of Medicine and Section of Clinical \\ Pathology, Mayo Clinic and Mayo Foundation, Rochester, Minn.)
}

In patients with cirrhosis and advanced hepatic failure, impairment of renal function with subsequent oliguria and azotemia may develop in the absence of primary renal disease; the prognosis when this complication occurs is grave (1-7). In recent reports, we have defined some of our experiences with patients in hepatic and renal failure $(7,8)$. The observations of others $(3-5$; 9-11) and ourselves (8) suggest that reduction in effective renal plasma flow (ERPF), developing particularly in patients with severe impairment of hepatic function and relatively resistant ascites, is the most important factor leading to renal complications.

Previous estimations of renal circulatory function (ERPF) in such patients have been based on para-aminohippurate $(\mathrm{PAH})$ clearance alone (3, $9,10)$, which may correlate poorly with renal plasma flow when renal function is severely impaired (12). In addition, the pathophysiologic mechanisms that may reduce renal hemodynamic function in hepatic disease have not been investigated comprehensively. Reductions in "effective" blood volume $(2,4,13)$, peripheral vascular resistance $(6)$, or arterial blood pressure $(1,3,6)$ have been postulated in this regard.

The purposes of the present study were to determine renal plasma flow in patients with cirrhosis and associated impairment of renal function

* Submitted for publication October 23, 1963 ; accepted January 30, 1964.

Supported in part by research grant AM-06908-01 from the National Institutes of Health, U. S. Public Health Service.

Abridgment of portion of thesis submitted by Dr. Baldus to the Faculty of the Graduate School of the University of Minnesota in partial fulfillment of the requirements for the degree of Master of Science in Medicine.

† Recipient of grant 2A-5259-Cl from the National Institutes of Health, U. S. Public Health Service. and to report the results of simultaneous measurements of certain variables that may influence the renal circulation in such patients. These include assessments of cardiac output, arterial blood pressure, renal vein pressure, difference in oxygen content between systemic artery and renal vein, and renal extraction of PAH. In addition, glomerular filtration rate, effective renal plasma flow, systemic vascular resistance, and renal vascular resistance were determined.

\section{Methods}

Observations were made on 23 adult patients with cirrhosis. The diagnosis of cirrhosis was based on clinical and laboratory evidence and, when necessary (nine instances), was confirmed by histologic examination of hepatic tissue. Cirrhosis was associated with chronic alcoholism in 13 patients and was of uncertain etiology in the remainder. None had a history of prior renal disease or significant abnormalities on urinalysis. $\mathrm{Pa}$ tients with evidence of recent gastrointestinal bleeding, cardiac disease, arterial hypotension or hypertension, diabetes mellitus, or septicemia were not considered for the study.

Patients were assigned before the study to the following groups according to the presence of ascites and its response to therapy, as earlier work had shown that changes in renal function correlated significantly with these factors (8): Group I-no ascites or ascites responding promptly to dietary restriction of sodium and thiazide diuretics; 14 patients (seven females and seven males, ages 17 to 67 years; mean, 45 years). Group IIascites resistant to dietary restriction of sodium and thiazide diuretics and requiring additional diuretic agents (glucocorticoids, spironolactone); nine patients (three females and six males, ages 17 to 78 years; mean, 56 years).

Two patients in group II (Cases 22 and 23) were azotemic (blood urea concentrations of 70 and $72 \mathrm{mg}$ per $100 \mathrm{ml}$, respectively).

Both clinical and biochemical evidence suggested more severe liver disease in group II than in group I patients. With but one exception (Case 21), all of the group II patients had moderate to severe degrees of ascites at the time of the study. Seven group I patients had ascites, 
but only of a mild or moderate degree. Two of the 14 group I patients and four of the nine group II patients had had previous episodes of hepatic precoma or coma. Serum albumin concentrations were less than $2.5 \mathrm{~g}$ per $100 \mathrm{ml}$ in the minority (five) of group I and in the majority (seven) of group II patients; jaundice (total serum bilirubin concentration more than $3.5 \mathrm{mg}$ per 100 $\mathrm{ml}$ ) was present in four patients in group $I$ and three in group II.

If prescribed previously, diuretics were discontinued at least 48 hours before the study. The patient fasted overnight, and all tests were performed while the patient was in the supine position with an indwelling catheter in the bladder. At least $500 \mathrm{ml}$ of water was administered by mouth before the procedure. Additional fluid was given by vein as $5 \%$ solution of dextrose in water. The total water load ranged from 1,000 to $1,500 \mathrm{ml}$.

Transfemoral catheterization of the right renal vein was performed under fluoroscopic control by the Seldinger technic (14). The catheter tip was advanced as far as possible into the hilus of the kidney and then withdrawn to the point where free flow was obtained on aspiration. Since the oxygen content of renal venous blood is considerably higher than that of caval blood (15), the position of the catheter was checked by determinations of oxygen saturation of blood aspirated from the catheter through a cuvette oximeter before, during, and after the renal function studies. In 14 of 18 patients undergoing catheterization of the right renal vein, samples of blood were obtained simultaneously from the renal vein and either the radial or femoral artery for the determination of $\mathrm{PAH}$ extraction ratios. The oxygen content of the blood aspirated simultaneously from the right renal vein and the arterial site was measured by the method of Van Slyke and Neill (16). Pressures were recorded simultaneously via a needle in the artery and from the right renal vein or inferior vena cava by strain-gauge manometers. The zero reference point was the mid-chest level.

Clearances of inulin and $\mathrm{PAH}$ were determined in all patients according to the methods described by Smith (17) with the chemical modifications of Schreiner (18) and Smith and associates (19), respectively. After the oral and intravenous fluid load, priming and sustaining infusions of inulin and $\mathrm{PAH}$ were administered in $0.45 \%$ saline. Three or four clearance periods, each of 15 to 20 minutes, were carried out in each patient, and the mean value is reported. When urine flow rates were less than $3 \mathrm{ml}$ per minute, the bladder was washed with sterile saline and emptied with air. Blood samples were aspirated simultaneously from the arterial site and the right renal vein 6 minutes before the midpoint of each clearance period for determination of inulin and PAH concentrations. Body surface area was based on body weight corrected for the weight of estimated ascites; all clearance values are corrected to a surface area of $1.73 \mathrm{~m}^{2}$. The statistical significance of the results was the same for corrected and uncorrected data.
Cardiac output was determined by the indicator dilution technic immediately preceding the clearance periods and repeated, in most instances, during the clearance studies. Five $\mathrm{mg}$ of indocyanine green dye was injected into either the inferior or superior vena cava, and blood was sampled from the indwelling arterial needle through a densitometer. The results were calculated from the dye-dilution curve according to the method of Hamilton, Moore, Kinsman, and Spurling (20). Since individual values agreed closely, the mean value was reported when two or three estimations were made.

By using standard formulas, the following calculations were made: $\mathrm{PAH}$ extraction ratio $\left(\mathrm{E}_{\mathrm{PAH}}\right)$ (21), renal plasma flow (RPF) (21), renal blood flow (RBF) (21), renal fraction of cardiac output (RFCO) (22), and (total) systemic vascular resistance $\left(R_{\mathbb{S}}\right)$ (23). Total renal vascular resistance $\left(R_{R}\right)$ was calculated from the formula, $(\mathrm{Pa}-\mathrm{Pv}) / \mathrm{RBF} \times 1,332$, where $\mathrm{Pa}$ is the mean arterial pressure in millimeters of $\mathrm{Hg}$; $\mathrm{Pv}$, the renal venous pressure in millimeters of $\mathrm{Hg}$; and $\mathrm{RBF}$ is renal blood flow in milliliters per second corrected to $1.73 \mathrm{~m}^{2}$ surface area.

\section{Results}

Inulin and $P A H$ clearances (Table $I$ ). Patients with relatively resistant ascites (group II) had significantly lower inulin and $\mathrm{PAH}$ clearances than those without ascites or with ascites responding promptly to therapy (group I) $(\mathrm{p}<0.01)$. PAH clearances were below normal in only three patients in group I, and inulin clearance was moderately reduced in one of these. In contrast, all group II patients exhibited moderate or severe reduction of $\mathrm{PAH}$ clearance, and inulin clearance was low in all but one.

The mean filtration fraction (F.F.) in group II was greater than that in group I (Table I). Elevated values were found in six of eight patients with resistant ascites tested (group II), but in only five of the 14 patients without ascites or with responsive ascites (group I).

Renal extraction of $P A H$ (Table $I$ ). PAH extraction ratios were determined in 14 patients and were normal $(>0.85)$ or only slightly reduced (0.85 to 0.82 ) in all but two patients (Cases 8 and 19), both of whom had unusually low values ( 0.45 and 0.52 , respectively). Mean values for the two groups were identical and subnormal (0.83) only because of an outstandingly low value in each group that did not affect the significance of the results. With exclusion of these values, the means were within the normal range (0.89 and 0.90 , respectively). 
TABLE I

Results of renal hemodynamic

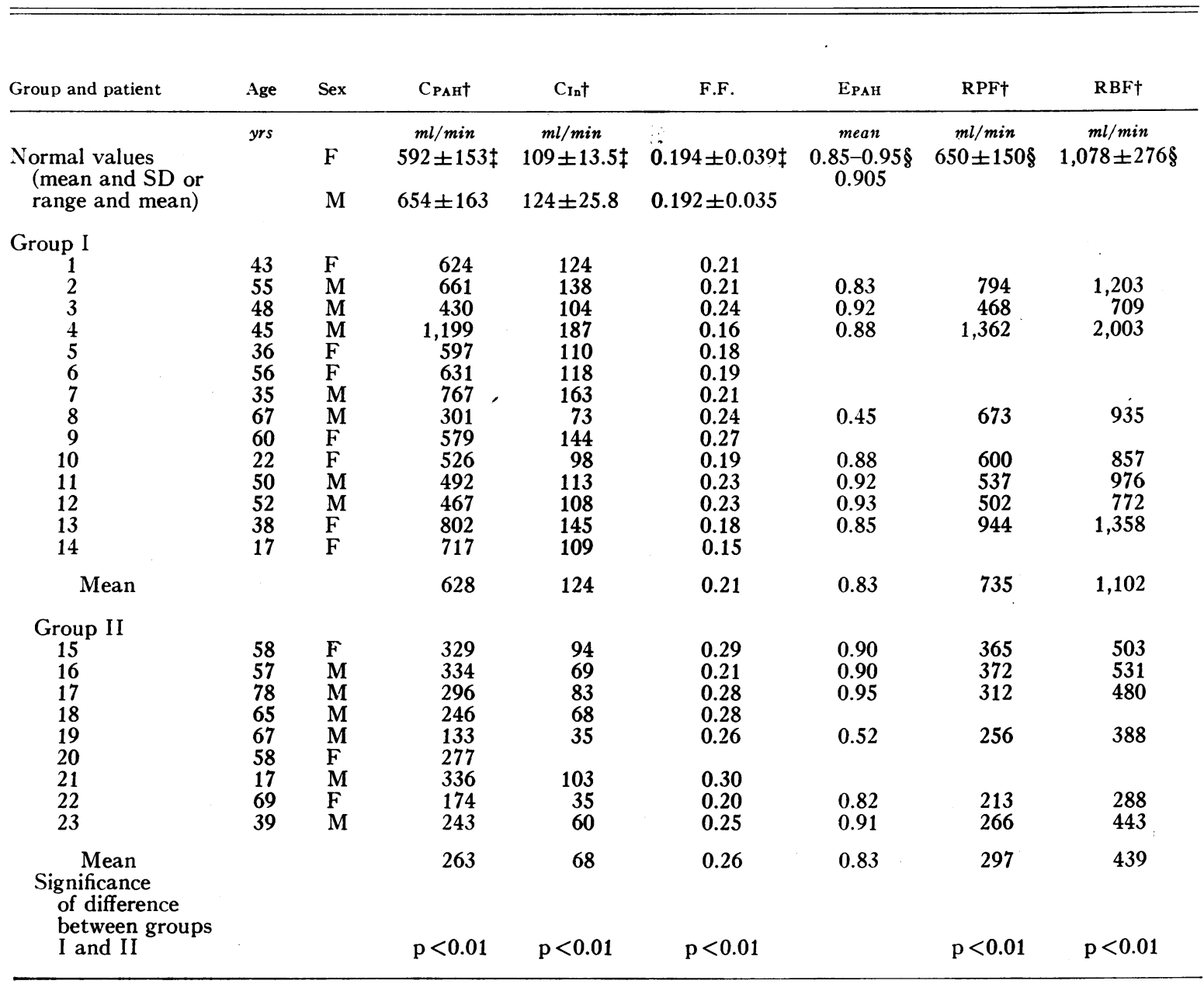

* Abbreviations: $C_{P A B}$, para-aminohippurate clearance; $C_{I_{n}}$, inulin clearance; F.F., filtration fraction; E $E_{P A H}$, paraaminohippurate extraction ratio; $R P F$, renal plasma flow; $R B F$, renal blood flow; $R_{S}$ (total) systemic vascular resistance; and $R_{R}$, renal vascular resistance.

† Corrected to $1.73 \mathrm{~m}^{2}$.

Renal plasma flow ${ }^{1}$ (Table I). The mean (total) renal plasma flow was normal in group I, but significantly lower in group II $(\mathrm{p}<0.01)$; values for patients in group I exceeded those in group II without exception (Table I). Renal plasma flow values were questionably reduced in one group I patient; another (Case 4) had an unusally high value, $1,362 \mathrm{ml}$ per minute. Exclusion of the latter value lowers the mean from 735 to $645 \mathrm{ml}$ per minute but does not alter the significance of the difference between the two groups. Renal plasma flow was reduced from 26 to $57 \%$

\footnotetext{
1 Corrected to $1.73 \mathrm{~m}^{2}$ surface area.
}

below the lower limit of normal in all patients in group II.

Renal vein and central venous pressure (Table $I)$. The mean renal vein pressure was higher in group II than in group I, and the difference was statistically significant $(p<0.02)$. Four of nine patients with resistant ascites (group II) had pressures exceeding any in patients without ascites or with responsive ascites (group I). Renal vein pressures were elevated in one patient in group I and in four in group II.

Central venous pressures, as measured in the superior vena cava or the supradiaphragmatic 
TABLE I

studies in cirrhosis*

\begin{tabular}{|c|c|c|c|c|c|c|c|}
\hline \multirow{2}{*}{\multicolumn{2}{|c|}{$\frac{\text { Cardiac output }}{\text { Renal fraction }}$}} & \multirow{2}{*}{$\frac{\begin{array}{c}\text { Cardiac } \\
\text { index }\end{array}}{L / \min / m^{2}}$} & \multirow{2}{*}{$\frac{\mathrm{Rs}}{\text { dyne-sec-cm-6}}$} & \multirow{3}{*}{$\begin{array}{c}\mathrm{R}_{\mathbf{R}} \\
\text { dyne-sec-cm-5} \\
4,000-10,000 \rrbracket \\
6,500\end{array}$} & \multirow{3}{*}{$\begin{array}{c}\begin{array}{c}\text { Arterial- } \\
\text { renal vein } \\
\mathrm{O}_{2} \text { difference }\end{array} \\
\text { vol } / 100 \mathrm{ml} \\
1.09-1.87^{* *} \\
1.42\end{array}$} & \multicolumn{2}{|c|}{ Pressure } \\
\hline & & & & & & \multirow{2}{*}{$\begin{array}{c}\begin{array}{c}\text { Arterial } \\
\text { (mean) }\end{array} \\
m m \mathrm{Hg} \\
75-110 \| \\
91\end{array}$} & \multirow{2}{*}{$\begin{array}{c}\begin{array}{c}\text { Renal } \\
\text { vein }\end{array} \\
m m \mathrm{Hg} \\
\begin{array}{c}10-14.6 \\
11.7 \dagger \dagger\end{array}\end{array}$} \\
\hline $\begin{array}{c}\% \\
17.5 \pm 4.68 \S\end{array}$ & $\begin{array}{c}L / \min \\
4.4-8.9 \| \\
6.6\end{array}$ & $\begin{array}{c}L / \mathrm{min} / \mathrm{m}^{2} \\
2.5-5.3 \| \\
3.5\end{array}$ & $\begin{array}{c}\text { dyne-sec-cm }{ }^{-6} \\
745-1,570 \| \\
1,130\end{array}$ & & & & \\
\hline $\begin{array}{l}15.9 \\
14.6 \\
27.3\end{array}$ & $\begin{array}{l}8.7 \\
8.9 \\
5.3 \\
8.2 \\
5.9 \\
6.4 \\
9.1\end{array}$ & $\begin{array}{l}5.7 \\
4.4 \\
2.9 \\
4.2 \\
4.0 \\
5.0 \\
4.6\end{array}$ & $\begin{array}{r}533 \\
703 \\
1,184 \\
817 \\
1,063 \\
786\end{array}$ & $\begin{array}{l}5,263 \\
8,805 \\
3,290\end{array}$ & $\begin{array}{l}1.8 \\
2.0 \\
1.7 \\
1.8\end{array}$ & $\begin{array}{l}65 \\
88 \\
86 \\
89 \\
81 \\
70\end{array}$ & $\begin{array}{l}7.0 \\
8.0 \\
6.5 \\
9.0\end{array}$ \\
\hline 18.6 & $\begin{array}{l}5.3 \\
6.0\end{array}$ & $\begin{array}{l}2.9 \\
3.5\end{array}$ & $\begin{array}{r}1,479 \\
663\end{array}$ & 8,197 & 1.2 & $\begin{array}{r}108 \\
80\end{array}$ & 12.0 \\
\hline $\begin{array}{r}11.7 \\
23.5 \\
8.5 \\
13.0\end{array}$ & $\begin{array}{l}6.2 \\
4.8 \\
9.2 \\
8.9 \\
8.1\end{array}$ & $\begin{array}{l}4.2 \\
2.4 \\
5.3 \\
5.9 \\
5.0\end{array}$ & $\begin{array}{r}1,034 \\
1,612 \\
689 \\
655\end{array}$ & $\begin{array}{l}7,079 \\
7,763 \\
8,209 \\
4,067\end{array}$ & $\begin{array}{l}2.1 \\
1.2 \\
1.4 \\
1.7\end{array}$ & $\begin{array}{r}84 \\
103 \\
86 \\
84\end{array}$ & $\begin{array}{r}8.0 \\
8.0 \\
6.5 \\
15.0\end{array}$ \\
\hline 16.6 & 7.2 & 4.3 & 935 & 6,584 & 1.7 & 85 & 8.9 \\
\hline $\begin{array}{r}6.7 \\
10.6 \\
11.6 \\
\\
9.3\end{array}$ & $\begin{array}{l}7.7 \\
5.3 \\
3.9 \\
5.4 \\
4.5 \\
5.3 \\
4.1 \\
5.6 \\
5.5\end{array}$ & $\begin{array}{l}4.4 \\
2.9 \\
2.4 \\
2.8 \\
2.4 \\
3.8 \\
2.6 \\
3.2 \\
3.2\end{array}$ & $\begin{array}{r}626 \\
987 \\
1,317 \\
1,223 \\
1,772 \\
1,292 \\
1,305 \\
826 \\
970\end{array}$ & $\begin{array}{r}9,514 \\
8,276 \\
10,656\end{array}$ & $\begin{array}{l}1.3 \\
1.8 \\
1.2\end{array}$ & $\begin{array}{r}70 \\
72 \\
78 \\
88 \\
108 \\
88 \\
78 \\
66 \\
89\end{array}$ & $\begin{array}{r}10.0 \\
16.5 \\
14.0 \\
18.0 \\
19.0 \\
7.0 \\
11.0 \\
10.0 \\
23.0\end{array}$ \\
\hline 8.6 & 5.3 & 3.1 & 1,146 & 12,364 & 1.7 & 82 & 14.3 \\
\hline $\mathrm{p}<0.02$ & $\mathrm{p}<0.01$ & $\mathrm{p}<0.01$ & $p=0.18$ & $\mathrm{p}<0.01$ & $\mathrm{p}=0.85$ & $p=0.65$ & $\mathrm{p}<0.02$ \\
\hline
\end{tabular}

$\ddagger-\dagger \dagger$ Normal values reported by: $\ddagger$ Smith $(21) ; \S$ Bergström and associates (12); \| Barratt-Boyes and Wood (24); I Lauson, Bradley, and Cournand (22); ${ }^{* *}$ Cargill and Hickam (15); †† Maxwell, Breed, and Schwartz (25). Where normal values are expressed as the mean and standard deviation, $\pm 1 \mathrm{SD}$ is taken as the normal range.

portion of the inferior vena cava, tended to be slightly lower than the corresponding renal vein pressures. However, the mean values for group I $(7.2 \mathrm{~mm} \mathrm{Hg} ; \mathrm{SE} \pm 0.9)$ and group II $(9.9 \mathrm{~mm}$ $\mathrm{Hg}$; SE \pm 1.8 ) were not significantly different.

Arterial-renal venous oxygen difference (Table $I)$. The average difference in oxygen content between arterial and renal venous blood was identical ( 1.7 vol per $100 \mathrm{ml})$ in groups I and II. This value is normal, and, with but three exceptions (Cases 3, 10, and 23), the individual values are within the normal range.

Cardiac output and cardiac index (Table I).
The mean cardiac output was higher in group I than in group II, and the difference was statistically significant $(p<0.01)$. Both values, however, were within the range of normal. Although cardiac outputs tended to be high normal in group I and low normal in group II, the variation of either group of values from the normal is of doubtful significance. Correction of the cardiac output for body surface area did not alter the statistical significance of the results (Table I). The mean values of cardiac indexes for both groups were within the normal range, and neither group differed significantly from the normal. 


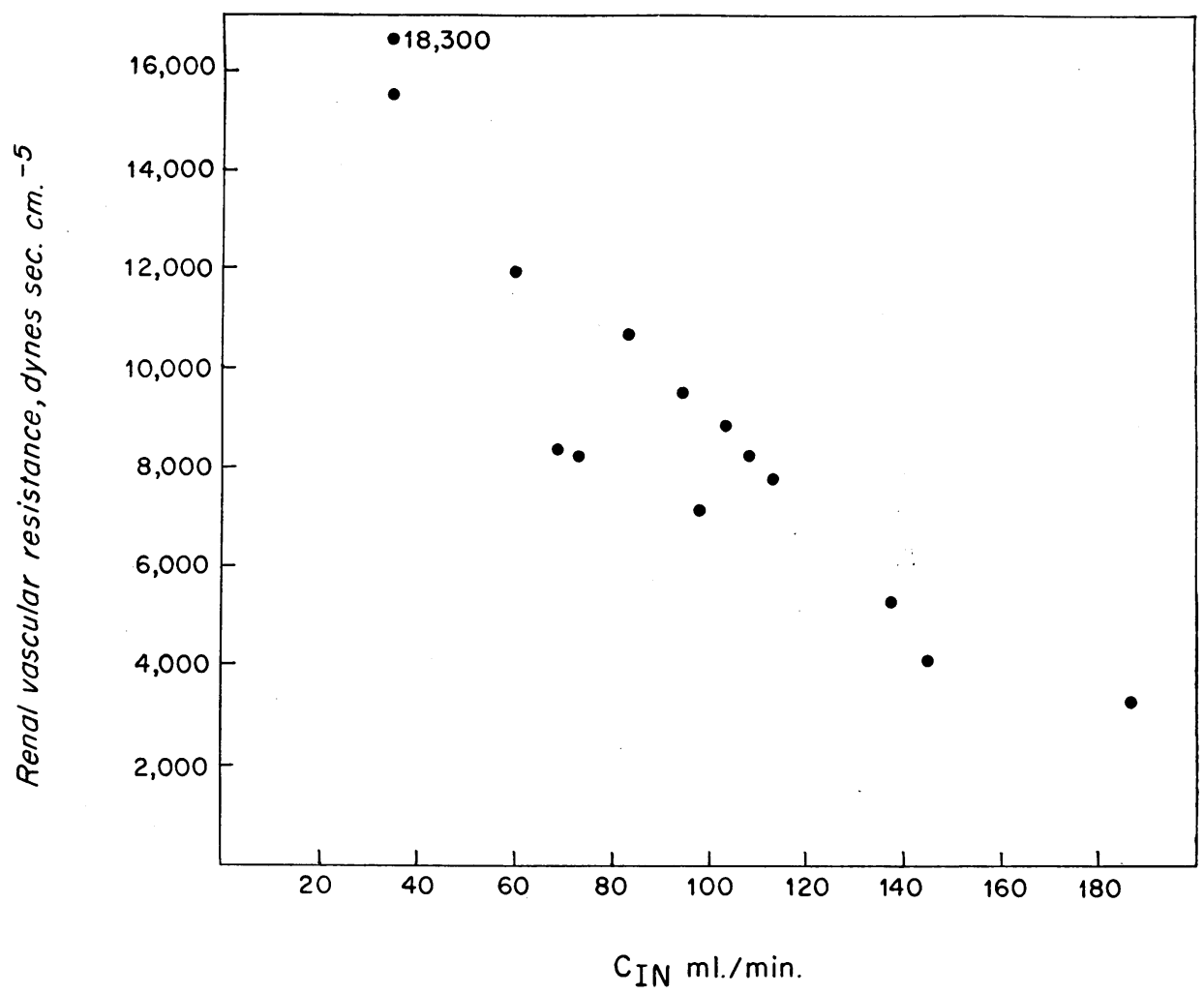

Fig. 1. Comparison of Renal vascular RESistance and inUlin clearance in patients WITH CIRRHOSIS.

Renal fraction of cardiac output (Table I). The mean renal fraction of cardiac output was significantly higher in group I than in group II patients $(p<0.02)$ (Table I). Overlap between the two groups occurred in only one instance. Two : patients in group I had values above and two, below the range of normal; all patients in group II had subnormal values.

Systemic vascular resistance (Table I). Mean values for systemic vascular resistance $\left(R_{\mathbb{S}}\right)$ were not significantly different in the two groups and were within the normal range. Five of 12 group I patients had $R_{\mathbf{S}}$ values below the normal range, whereas this occurred in only one group II patient (Case 15).

Renal vascular resistance (Table I). Since renal blood flow was lower in group II than in group I and the mean arterial pressures were similar in the two groups (Table $I$ ), the mean total renal vascular resistance $\left(R_{R}\right)$ was higher in group II. The difference was highly significant $(p<0.01)$. Only one group II patient (Case 16) had a value below the highest value in group
I. With the exception of one subnormal value (Case 4), all group I patients had $R_{R}$ values within the range of normal. In contrast, four of the six patients tested in group II had elevated values. Mean arterial pressures were similar in the two groups, both with regard to average values and ranges.

Comparison of individual $R_{R}$ and inulin clearance values revealed a striking inverse correlation (Figure 1) as would be anticipated. Other parameters, however, including cardiac output and renal vein pressure, which were significantly different in the two groups, failed to show a significant relationship when compared individually with inulin clearance and renal plasma flow.

\section{Discussion}

Renal extraction of PAH was normal or only slightly reduced in the majority of patients in both groups. This, together with the reduced clearances of inulin and PAH measured in those with resistant ascites, confirms previous impressions that the disorder of renal function in some 
patients with hepatic failure is primarily due to diminution of renal plasma flow $(3,5,26)$. Several factors that might influence renal circulation were therefore considered.

The normal or only slightly reduced extraction ratios in both groups of patients militate against significant arteriovenous shunting of blood within the kidney similar to that occurring elsewhere in the body in cirrhosis (27-29). The normal arterial-renal venous oxygen differences support this, but the range of values was wide and the method relatively insensitive. Renal vein pressures were usually higher in patients with impairment of renal function, although seldom elevated far above the normal range. The degree of elevation of renal vein pressure appears insufficient alone to account for the reduction of renal plasma flow, since much more substantial increments produce less significant reductions of renal hemodynamic function in animals (30-31) and man (25). It has been suggested that the increased renal vein pressure secondary to the presence of ascites (32) or abdominal compression (33) causes reduction of glomerular filtration rate and effective renal plasma flow in man, but we have been unable to influence these measurements by the removal of ascites (8), and studies in dogs with experimentally induced ascites have yielded similar conclusions (34).

Reductions in cardiac output, peripheral vascular resistance, and arterial blood pressure $(1,3,6)$ have been suggested as causes of renal failure in cirrhosis. Lancestremere and his colleagues (35) found that the cardiac output was normal or elevated under such circumstances, and our results showed that the cardiac output was usually within the normal range. There could have been a small reduction of doubtful relevance from previous values, however, as higher measurements were obtained in group I patients. Despite the normal mean cardiac output in both of our groups of patients, the renal fraction of cardiac output was significantly lower in those with impaired renal function. Diversion of a greater than normal proportion of the cardiac output to nonrenal areas is therefore implied, but no attempt was made to quantitate blood flow to other regions. Certainly, there was no significant difference between the two groups of patients with regard to mean arterial blood pressure or systemic vascular re- sistance. As a low systemic vascular resistance and an increase in the peripheral circulation (28, 36) have been reported in patients with cirrhosis, however, such changes in group II patients could have been masked by the contribution of elevated renal vascular resistance to the total systemic vascular resistance.

Total renal vascular resistance was significantly greater in patients with the greater impairment of renal hemodynamic function (group II) than in others (group I); this increase in resistance reflects a reduction of renal blood flow without a concomitant fall in mean arterial pressure. This increase in resistance offered by the renal vasculature, therefore, could account for the diminished total renal plasma flow and the low renal fraction of the cardiac output. Whether such a change represents a causal mechanism for the renal circulatory changes or a compensatory response to other circulatory alterations is uncertain. Similarly, the site of increased resistance within the renal vasculature, together with its possible relationship to factors more directly associated with hepatic disease, cannot be specified. Failure of inactivation or the production of a substance affecting the renal vessels as a result of hepatic failure are obvious considerations. Alternatively, Onnis, Shumacker, and Bounous $(37,38)$ demonstrated a dramatic reduction of renal blood flow after occlusion of the portal vein, hepatic artery, or celiac axis in dogs. As this effect was abolished by prior sympathectomy and splanchnicectomy, reflex renal vasoconstriction secondary to interference with the hepatic circulation was implicated as a cause of the diminished renal blood flow. In addition, renal circulatory failure in cirrhosis occurs particularly in patients with relatively resistant ascites, and elevated plasma angiotensinase activity has been found in patients with hepatic disease $(39,40)$. Interrelationships between the renin-angiotensin-aldosterone system and increased plasma angiotensinase activity or renal perfusion have been postulated, but are as yet indeterminate $(41,42)$.

\section{Summary}

Studies of the renal circulation were carried out in patients with cirrhosis and varying degrees of hepatic decompensation. Those with relatively resistant ascites were found to have a 
disorder of the renal circulation characterized by a reduced renal plasma flow despite normal cardiac output, indicating diversion of a greater than normal proportion of the cardiac output to nonrenal areas. Increased total renal vascular resistance in this group of patients suggested renal vasoconstriction as the cause of the diminished renal plasma flow.

\section{Acknowledgment}

The authors are indebted to Dr. J. T. Shepherd for his help with the catheterization studies and his advice and to Mr. Robert Gage for statistical analysis of the data.

\section{References}

1. Hecker, R., and S. Sherlock. Electrolyte and circulatory changes in terminal liver failure. Lancet $19562,1121$.

2. Papper, S. The role of the kidney in Laennec's cirrhosis of the liver. Medicine (Baltimore) 1958, 37, 299.

3. Papper, S., J. L. Belsky, and K. H. Bleifer. Renal failure in Laennec's cirrhosis of the liver. I. Description of clinical and laboratory features. Ann. intern. Med. 1959, 51, 759.

4. Vesin, P. Late functional renal failure in cirrhosis with ascites: pathophysiology, diagnosis and treatment in Aktuelle Probleme der Hepatologie: Ultrastruktur, Steroidstoffwechsel, Durchblutung, Leber und Niere, G. A. Martini, Ed. Stuttgart, Georg Thieme, 1962, pp. 98-110.

5. Tyler, J. M., J. L. Jeffries, and C. E. Wilder. A study of the renal blood flow by nitrous oxide technique in normal and oliguric patients with cirrhosis of the liver (abstract). Clin. Res. 1962, 10, 194.

6. Mashford, M. L., W. A. Mahon, and T. C. Chalmers. Studies of the cardiovascular system in the hypotension of liver failure. New Engl. J. Med. 1962, 267, 1071.

7. Baldus, W. P., R. N. Feichter, and W. H. J. Summerskill. The kidney in cirrhosis. I. Clinical and biochemical features of azotemia in hepatic failure. Ann. intern. Med. 1964, 60, 353.

8. Baldus, W. P., R. N. Feichter, W. H. J. Summerskill, J. C. Hunt, and K. G. Wakim. The kidney in cirrhosis. II. Disorders of renal function. Ann. intern. Med. 1964, 60, 366.

9. Shaldon, S., and G. Walker. Jaundice and acute renal failure in Aktuelle Probleme der Hepatologie: Ultrastruktur, Steroidstoffwechsel, Durchblutung, Leber und Niere, G. A. Martini, Ed. Stuttgart, Georg Thieme, 1962, pp. 118-123.

10. Onen, K. H. Renal haemodynamics in hepatic cirrhosis. Lancet 1960, 1, 203.
11. Shear, Leroy, P. W. Hall, and G. J. Gabuzda. Studies of the renal failure associated with hepatic cirrhosis (abstract). J. Lab. clin. Med. 1962, 60, 1017.

12. Bergström, J., H. Bucht, J. Ek, B. Josephson, H. Sundell, and L. Werkö. The renal extraction of para-aminohippurate in normal persons and in patients with diseased kidneys. Scand. J. clin. Lab. Invest. 1959, 11, 361.

13. White, A. G. Clinical Disturbances of Renal Function. Philadelphia, W. B. Saunders, 1961, pp. 291-295.

14. Seldinger, S. I. Catheter replacement of the needle in percutaneous arteriography. A new technique. Acta radiol. (Stockh.) 1953, 39, 368.

15. Cargill, W. H., and J. B. Hickam. The oxygen consumption of the normal and the diseased human kidney. J. clin. Invest. 1949, 28, 526.

16. Van Slyke, D. D., and J. M. Neill. The determination of gases in blood and other solutions by vacuum extraction and manometric measurement. I. J. biol. Chem. 1924, 61, 523.

17. Smith, H. W. Principles of Renal Physiology. New York, Oxford University Press, 1956, pp. 209-210; 212-213.

18. Schreiner, G. E. Determination of insulin by means of resorcinol. Proc. Soc. exp. Biol. (N. Y.) 1950, 74, 117.

19. Smith, H. W., N. Finkelstein, L. Aliminosa, B. Crawford, and M. Graber. The renal clearances of substituted hippuric acid derivatives and other aromatic acids in dog and man. J. clin. Invest. 1945, 24, 388.

20. Hamilton, W. F., J. W. Moore, J. M. Kinsman, and R. G. Spurling. Simultaneous determination of the pulmonary and systemic circulation times in man and of a figure related to the cardiac output. Amer. J. Physiol. 1928, 84, 338.

21. Smith, H. W. The Kidney: Structure and Function in Health and Disease. New York, Oxford University Press, 1951 , pp. 46; 163-164; 544-545.

22. Lauson, H. D., S. E. Bradley, and A. Cournand. The renal circulation in shock. J. clin. Invest. 1944, 23, 381.

23. Cournand, A., R. L. Riley, S. E. Bradley, E. S. Breed, R. P. Noble, H. D. Lauson, M. I. Gregersen, and D. W. Richards. Studies of the circulation in clinical shock. Surgery 1943, 13, 964.

24. Barratt-Boyes, B. G., and E. H. Wood. Cardiac output and related measurements and pressure values in the right heart and associated vessels, together with an analysis of the hemodynamic response to the inhalation of high oxygen mixtures in healthy subjects. J. Lab. clin. Med. 1958, 51, 72.

25. Maxwell, M. H.; E. S. Breed, and I. L. Schwartz. Renal venous pressure in chronic congestive heart failure. J. clin. Invest. 1950, 29, 342.

26. Vesin, P., H. Traverso, H. Hirsch-Marie, and R. Cattan. L'insuffisance rénale circulatoire spontanée 
du cirrhotique. Son évolution. Sem. Hôp. Paris 1962, 38, 3598.

27. Rydell, R., and F. W. Hoffbauer. Multiple pulmonary arteriovenous fistulas in juvenile cirrhosis. Amer. J. Med. 1956, 21, 450.

28. Abelmann, W. H., H. J. Kowalski, and W. F. McNeely. The hemodynamic response to exercise in patients with Laennec's cirrhosis. J. clin. Invest. 1955, 34, 690.

29. Silverstein, E. Peripheral venous oxygen saturation in patients with and without liver disease. J. Lab. clin. Med. 1956, 47, 513.

30. Selkurt, E. E., P. W. Hall, and M. P. Spencer. Influence of graded arterial pressure decrement on renal clearance of creatinine, p-aminohippurate and sodium. Amer. J. Physiol. 1949, 159, 369.

31. Blake, W. D., R. Wégria, R. P. Keating, and H. P. Ward. Effect of increased renal venous pressure on renal function. Amer. J. Physiol. 1949, 157, 1.

32. Gordon, M. E. The acute effects of abdominal paracentesis in Laennec's cirrhosis upon exchanges of electrolytes and water, renal function, and hemodynamics. Amer. J. Gastroent. 1960, 33, 15.

33. Bradley, S. E., and G. P. Bradley. The effect of increased intra-abdominal pressure on renal function in man. J. clin. Invest. 1947, 26, 1010.

34. Gilder, H., G. N. Cornell, and H. J. Mannix. Renal function in experimental ascites. Metabolism 1956, $5,51$.
35. Lancestremere, R. G., P. L. Davidson, L. E. Earley, F. J. O'Brien, and S. Papper. Renal failure in Laennec's cirrhosis. II. Simultaneous determination of cardiac output and renal hemodynamics. J. clin. Invest. 1962, 41, 1922.

36. Murray, J. F., A. M. Dawson, and S. Sherlock. Circulatory changes in chronic liver disease. Amer. J. Med. 1958, 24, 358.

37. Onnis, M., H. B. Shumacker, Jr., and G. Bounous. Response to occlusion of the portal vein. Blood pressure and renal blood flow. Arch. Surg. 1962, 85, 897.

38. Onnis, M., H. B. Shumacker, Jr., and G. Bounous. Blood pressure and renal blood flow response to occlusion of visceral arteries. Ann. Surg. 1963, $157,56$.

39. Klaus, D., H. Kaffarnik, and H. Pfeil. Untersuchungen über die Serum-Angiotensinase. II. Klinische ergebnisse beim Hochdruck und bei Leberrerkrankungen. Klin. Wschr. 1963, 41, 380.

40. Biron, P., W. P. Baldus, and W. H. J. Summerskill. Unpublished data.

41. Davis, J. O. Adrenocortical and renal hormonal function in experimental cardiac failure. Circulation 1962, 25, 1002.

42. Laragh, J. H., P. J. Cannon, C. J. Bentzel, A. M. Sicinski, and J. I. Meltzer. Angiotensin II, norepinephrine, and renal transport of electrolytes and water in normal man and in cirrhosis with ascites. J. clin. Invest. 1963, 42, 1179. 